Within the limits of normal psychic functioning we are trequently conscious of the play of contrasting notions and emotions with correlative intuitions or impulsions to move. ment on the one hand and inhibitions and repressions on the other.

Whether it be in the form of deliberation and reasoning to a conclusion without immediate action of a gross kind, or the weighing of the pros and cons with determination to immediate action, the conflict between the opposing tendencies, intense though it may be, does not greatly disturb the personality, provided there is a definite issue and harmonious adaptation. Where, on the contrary, there is vacillation and indetermination consequent upon the monopolization of consciousness by contending notions and emotions, conflict becomes distinctly morbid, because on tlie one hand it restricts psychic action within unduly narrow limits, preventing the ntilization of a great part of the mental capital, and on the other hand it interferes with the reception and assimilation of stimuli from without which are the constant accompaniments of normal relations with the environment.

It is clear that the psychology of conflict which has occupied such a prominent place in recent literature cannot be adequately and rationally discussed without a full appreciation of the part played by contrast in the normal psychic mechanism, more particularly in relation to all the processes involved in ideation and emotion, attention, discrimination, judgement, choice, volition, and inhibition.

1 Professor J. M. Baldwin REFERENCEs.

William William James: T'extbook of Pryrho'gy, 1892. 'B Professor Leonaldo
Bianchi: The Mechanism of the Brain, 1622.

\section{EPILEPSY AND GUNSHOT WOUNDS OF THE HEAD.}

\section{[Abstract.]}

Dr. W. Aldren Turner (London) said that out of 18,000 cases of gunshot wounds of the head under the Ministry of Pensions 800, or less than 5 per cent., have developed epilepsy. It is met with in two classes of case: (1) following slight trauma without obvious injury to the skull or brain; (2) true traumatic epilepsy, following injury to the skull or brain, and associated usually with paralytic symptoms. In the first class it is often difficult to say how far the fit may ke attributable to the head injury, but it is an impertant point on account of the number of ex-service men who have received a minor gunshot wound of the head and who state they have in consequence become epileptic.

In true traumatic epilepsy the disability is characterized by seizures having the characters of ordinary epilepsy which may follow injury of any part of the brain except the cerebellum, independent of the extent or severity of the lesion. The time of onset. of fits after injury varies from six months to two or three years. Jaclisonian epilepsy is rare in comparison with the incidence of ordinary traumatic epilepsy.

'Traumatic epilepsy following wounds of the brain is attributable in part to the injury, but in greater part to the constitutional disposition of the patient; local conditions at the seat of injury only in part explain the phenomena. The very small percentage of cases of gunshot wound of the head which develop epilepsy is remarkable, especially when it is known that "anchoring " of the brain to the scalp and the extensive destruction of the skull associated with paralytic symptoms are, in the majority of cases, not associated with epilepsy.

THE Medica! Officer of Health for Cairo City in his recently issued report for $19<0$ states that during that year 40,054 vaccinations were carried out by the medical officers of the inspectorate and districts. Of these 30,623 were primary vaccinations, principally of native children. The corresponding figures were 27,292 in 1919 , and 25,613 in 1918 . The number of cases of small-pox notified during 1920 was 157, as compared with 1,455 in the previous year.

THE second international congress of military medicine and pharmacy will be held in Rone next spring, beginning on May 28th. The first congress was held in Brussels in July, 1921. 'The chief subjects for discussion at Rome will be the general principles of the evacuation of the sick and wounded, the co-operation of civil and military authorities in the pre. vention of disease, chemical laboratories in the fleld, and the treatment of penetrating wounds of the chest. The subscription is fr. 25. Further particulars can be obtained from the Director of the Giornale di Medicina Militare at the Palazzo del-Ministere della-Guerra, Rome.

\section{THE SURGICAL TREATMENT OF GASTRO- JEJUNAL AND JEJUNAL ULCERATION.}

BY

GARNETT WRIGHT, M.B., F.R.C.S., HONORARY SURGEON, SALFORD ROYAL HOSPITAL.

I HAvE elected to bring before your notice to-niglit a record of surgical failures, believing that one way to progress lies in the study and analysis of our unsuccessful cases.

While the surgical treatment of gastric and duodenal ulcev is for the most part highly successful there remains a percentage of patients who are not cured or even relieved by surgical measures, and of that residuum probably the most unsatisfactory are the subjects of secondary ulceration, either gastro-jejunal or jejunal. I say they are the most unsatis. factory because not only are they not cured, but very often they are in a worse condition than they were before operation. This complication has occurred most frequently after the operation of gastro-enterostomy, and it has been stated that it does not follow operations of partial gastrectomy. This, however, is not true, and cases are now beginning to bo reported after these operations. The reason for this falso impression is that until recently the operation of partial gastrectomy has largely been confined to cases of carcinoma, which practically never develop secondary ulcers, the neces. sary factor of hyperchlorhydria being absent. Now that partial gastrectomy has become established as a surgical treatment for gastric ulcer I have no doubt that an increasing number of cases will occur.

No variely of operative procedure on patients suffering from gastric or duodenal alcer is immune from this complication, whether it be gastro-enterostomy, partial gastrectomy, excision of the ulcer, or-pyloroplasty. From the published records, horvever, it would seem to be specially prone to follow operations for duodenal ulcer, operations en-Y, and with entero-anastomosis. The reason for this is the high degree of hyperchlorhydria which is asually found in duodenal ulcer, and, in the case of the special types of operation, the fact that the unneutralized gastric contents come into coutact with jejunal mucosa.

It is believed by some that secondary ulcer is more likely to follow anterior than posterior gastro-enterostomy. It is very difficult to form a reliable opinion on this point, but what is evident from a study of the recorded cases is that t:ue jejunal ulceration is relatively more frequent after anterior gastro-enterostomy, probably because the farther we descend the intestine the less tolerant it is to the action of the gastric juice.

'lise actual cause of the secondary uiceration is as obscure as the cause of the original ulcer for which the operative treatment was undertaken. That it is due in some way to the action of the gastric juice is evident from the situation of the ulceration-for example, on the anastomotic opening, on the jejunum opposite the stoma, on the efferent loop just beyond the anastomosis. That it is associated with hyperacidity is also beyond doubt, and probably this acidity is a factor in the production of the ulceration. We are still, however, in the dark as to the causation of the hyperacidity.

Errors in technique have been held to be largely responsib?e, especially the use of a Murphy's button or an unabsorbable con. tinuous suture. In a series of cases I collected and published in the British Journal of Surgery (vol. vi) there were 14 cases out of 145 where Murphy's button liad been used and 13 where an unabsorbable suture played an important part in the pro. duction of the ulceration. Nevertheless cases have occurred where catgut only has been employed.

The use of clamps and other teclinical methods have been blamed, but there is no definite proof that such methods are especially prone to be followed by ulceration. We are eon. fronted with the fact that secondary ulceration may follow any teclınique and may even occur in the absence of hyperchlorhydria, though this is not common. We are driven to the conclusion, therefore, that the cause of the original ulceration is still at work in these cases, and has not been removed by the operation, and this is borne out by the great liability to recurrence in these patients, many of whom have been operated on repeatedly.

When we know the cause of gastric and duodenal ulceration we shall also know the cause of gastro-jejunal and jejunal ulceration. 
My object now is to analyse the small series of cases that have been under my care, with special reference to the surgical treatment that has been cmployed, and, if possible, to come to some conclusion as to the methods which are most likely to be successful. Most of these patients have been under observation for some considerable time-a condition which is essential if we are to form a true estimate as to the results of treatment. Many of the cases reported on as cured have been followed for only a few months after operation, a period which is much too short. My experience is that relapse is very common and may come on a year or more after operation.

I have had under my care seven cases of secondary ulcer, five of whom were originally operated on by me and two by other surgeons. Multiple operations have been done in most cases, and the results have been disappointing. I propose to give only a bare outline of the cases, and not to bore you with clinical details. The first three of these have been reported previously.

CASE I.

Male, aged 32. On May 6th, 1916, he had an anterior gastroenterostomy for stenosis of the duodenum due to nlceration. Tro rows of silk suture were used. In October, 1916, he had as sudden azute pain in the abdomen, and after this he had more or less con tinuous pain until December, 1916, when I reopened him. He had an uicer of the efferent loop just beyond the anstomosis and adherent to the anterior abdoninal wall. The ulcer was excised, and a silk suture, which was found lying in it, was removed. On October 3rd, 1917, he was living in Leeds, and had a sudden perforation, for which he was operated on in the Leeds Infirma.r. the ulcer being sutured. Pain persisted after this operation, so that Foperated on him ag in on November 29th, 1917. The ulcer was gtill present in the same place, and was still adherent to the anterior ab!ominal wall. The gastro-enterostomy was cut off, the opening in the stomach closed, and the affected loop of jejunum was resected and joined up by lateral anastomosis. A posterior no-loop gastro-enterostomy was then made, catgut alone being used. The patient remained well until the early part of 1919 , when he began to have more indigestion. This persisted for some time, and did not really disappear until I fitted him with an abdominal support, as he hal a fair desree of ptosis. Since then he states that he has felt a different man, and is now in good licalth.

Male, aged 40. He was operated on by another surgeon for duodenal ulcer in December, 1915, the operation being posterior gastro enterostomy with two rows of linen thread. Pain recurred in a few month's time, and he was reopened by the same surgeon in September, 1916, who performed an entero-auastomosis. II induration was noted at the gastro-enterostomy stoma, and a length of linen thread was attached to it. This was removed when the entero-anastomosis was made. The symptoms rapidly recurred, and in December, 1917, I was asked to take him over, as $h$ is surgeon hal to be absent on military service. On Decenber $22 n d, 1917$, I operated on him, and cut off the anastomosis which was the site of ulceration, and closed the openings in the stomach and the jejunum by a plastic operation. I excised the old duodenal ulcer, which was healed, by an elliptical incision, closing this trausversely. The pylorus being patent, nothing. further was required or done. Siuce that time the patient has been completely tree from symptoms, and is now in perfect health.

\section{CASE III.}

Male, aged 43. Perforated duodenal ulcer in January, 1912 Suture of the perforation and posterior gastro-jejuuostomy with
silk sutures. Indigestion reappeared in two years time. Second operation, April 25th, 1918. Much induration and contraction of the stoma and transverse mesocolon were found. The gastroenterostomy opening was excised, the opening in the stomach was closel, and the cut ends of the jejunum were joined by end-to-end union. Radiographic examination later showed fair vermeability of the pylorus, so nothing more was done. The putient remained in good health until abont six months ago. Since then symptoms of stenos:s have gradually developed, for which I propose to operate.

Case IV.

Male, aged 49. Operation in August, 1918, for blee:ling duodenal ulcar of three years' standing; posterior gastro-enterostomy and infolding of the ulcer; catgut alone was used for the sutures. Pain recurred six weeks after the operation. He was operated upon again on January 17th, 1920. An ulcer was fornd on the mesenteric again on January $17 \mathrm{th}, 1920$. An ulcer was found on the mesenteric
lyorder of the jejun um opposite the stoma. The anastomosis itself was free from ulceration. The anastomosis and jejunal loop were resected, the gastric opening was closed, and the jejunum joined by encl-to-end union. A Kocher's gastro-duodenostomy wa s made because of the stenosis of duodenum. After a period of freedom lasting several months the symptoms recurred and he was again reopened on Deceuber 31st, 192). The gastro-duodenostomy opening was found to be almost obliterated, and a posterior gastroenterostomy was again made. The patient is now free from ulcera. tion, but has some reflux vomiting owing to adhesions round the efferent loop-iso doubt the result of repeated operative interference.

$$
\text { Case v. }
$$

Male, aged 36. Operation, February 17th, 1917. Posterior gastroenterostom then he had reculrence of pain and vomitiug. A second operation was done in June, 1920. Gastro-jejunal ulceration, with stenosis of stoma, was found, and the pylorus and duodenum were also stenosed. Pyloroplasty was done, resection of the stoma being left for a future sitting. This gave so much relief that nothing more has been done. For six months he was comp!etely free from pain, but since then he has had occasional slight attacks of indigestion lasting about three days. His weight at the time of the second operation was 10 st.; now it is 12 st. $3 \mathrm{lb}$.

Male, aged 40. Operation for perforated duodenal ulcer, October, 1919. Suture and posterior gastro-enterostomy (catgut only) Recurrence of pain three months later. Radiographically circular spasm of stomach was seen starting at stoma. Second operation. February, 1920. A small ulcer was found on the upper angle of the stoma. It was necessary to open the stomach to confirm this. The ulcer was excised locaily, the resulting opening being closed with catgut sutures. The patient was readmitted to hospital on December 8 th, 1920, suffering from severe haemorthage. He was too ill for operation, and one pint of blood was transfused. He had a second less severe haemorrhage on December 12th, and then began to improve. On January 21st, 1921, he was operated on, and a thickened and stenosed stoma was found; the site of active ulceration. An attempt at pyloroplasty failed to produce a satisfactory opening, and therefore a partial gastrectomy was done, the anastomosis being included in the portion removed. The tech. nique employed was a posterior Polya en-Y as advocated by Moynihan.

The patient complained of pain again in September, 1921, and still has pain and, he says; vomitin'. He has been admitted to hospital and dieted carefully, and never vomits while he is in, and also he gains in weight. Radiographic exanination reveals nothing, the stump of the stomach emptying freely.

Male, aged 47. Gastro-enterostomy in 1914 by another surgeon for pyloric stenosis. Relief for three years and then recurrence of pain. Latterly he has lost weight, but does not vomit unless he makes himself sick to relieve the pain. The radiographic report is as follows: "Stomach atonic and four inches low; moderately slow emptying through stoma." Second operation, December 6th, 1921. Active duodenal ulcer a therent to head of pancreas is still present. Stoma is much thickened and stenosed. The mesocolon is thickened and contracted. Partial gastrectomy by posterior Polya method was done.

When we analyse the methods employed in this small series we find that three have been left with the food taking the normal channel through the pylorus-namely, cases 2,3 , and 5. In two of these three cases no operation on the pylorus was necessary to enable the food to pass. In one a plastic operation was required. In two the gastro-enterostomy was cut off and in one it was left untouched-namely, case 5 . The striking feature in this case was the rapid subsidence of symptoms when the plastic operation enabled the gastric contents to pass normally, and so relieved the stoma of the necessity of acting. . The relief experienced was comparable to that afforded by the operation of gastro-enterostomy in duodenal ulcer with partial stenosis.

The results are: Cure in one case, where there was no pylc:ic stenosis originally, and where the original ulcer was excised at the time of the last operation. Relief for three years in a case where the pylorus was deformed, and then gradual onset of stenosis of the pylorus. Complete relief for six months and then partial recurrence of symptoms in the case where a plastic operation on the pylorus was necessary.

'Two cases are left with a posterior no-loop gastroenterostomy. In one (Case 1) there was a recurrence of symptoms about fifteen months after the last operation; but he is now well and eating ordinary food. I think the recurrent symptoms were possibly due to ulceration, though he has derived great benefit from wearing a ptosis support. The other patient (Case 4) is cured as regards ulceration, but has some reflux vomiting, which is controlled by gastric lavage.

Two patients have had partial gastrectomy (Nos. 6 and 7) No. 7 is too recent for any reliable opinion to be formed. No. 6 has pain, but how far one can rely on his statements is a little doubtful as he is a pensioner, and while he is under observation in hospital he does not complain much. It is somewhat significant, however, that he has a total acidity of 127 and free $\mathrm{HCl}$ of 60 .

'The operative methods at our disposal are:

1. Local Excision of the Vlcer.-This was employed on two occasions in the present series, and it was successful in neither.

2. Cuiting off the Gastro-enterostomy, and the formation of a fresh anastomosis.- This was employed in Cases 1 and 4, two fresh anastomoses being necessary in Case 4 , the gastro-duodenostomy done at the second operation being closed by ulceration. The ul timate result is moderately successful in both.

3. Partial Gastrectomy.-Employed on two occasions in the present series. Probable recurrence in one patient. The other operated on too recently for report. The drawback to this opera tion is that one is almost driven to an operation en-Y. 
4. Cutting off the Gastro-enterostomy, and Restoration of the Natural Cliannel.-Where there is no pyloric stenosis, as in Case 2 this is the most satisfactory operation of all. Even where a plastic operation is necessary the ultimate outlook is fairly good. It is essential tliat the original ulcer, if still present, should be excised, and if this had been done in Case 3 I think that we should have avoided the stenosis which has gradually come on. The reason I did not do this was that the original ulcer was a perforating one, and the adhesions round the pylorus and duodenum were very dense.

\section{Conclusicns.}

The conclusions one has arrived at are:

1. That operations for gastric and duodenal ulcers are to be regarded only as incidents in the treatment, and that diet, etc., and medical treatment should be persisted in after the operation for a long period.

2. That in addition to care in the technique it is preferable to use an absorbable suture material.

3. That any possible primary cause for the ulceration, such as an inflamed appendix or gall bladder, should be sought for, and if found removed.

4. That it is a mistake to occlude or otherwise deform the pylorus. This is unnecessary for the cure of the ulcer and deprives us of our best line of retreat should secondary ulcers form.

5. That when secondary ulcers have formed it is best to cut off the gastro-enterostomy and restore the natural channel if necessary by a plastic operation. The original ulcer, if still present, should be excised at the same time.

6. Where this is impossible and a fresh anastomosis is necessary operations of the $Y$ type should be avoided.

7. Care is required after the operation for a long time.

8. That when one is operating for a perforated ulcer it is better to avoid gastro-enterostomy if possible, as so many of these cases recover completely without any recurrence of symptoms after suture of the perforation.

I have only touched on the subject of simple uncomplicated secondary ulcer to-night. The consideration of the various complications and their treatment would be much too wide a subject for the time at my disposal, and I have had none of these difficult cases under my care.

\section{PROSTATECTOMY IN A CASE OF DIABETES INSIPIDUS.

$$
\text { BX }
$$

\section{J. FINLAY ALEXANDER, M.D.CAMB., $\triangle N D$}

\section{F. S. KIDD, F.R.C.S.ENG.}

The performance of prostatectomy in a case of diabetes insipidus does not appear to have been previously noted, and the presence of giant bladder, without evidence of renal or vesicle failure, is of interest.

\section{Clinical History.}

The patient, a grocer, aged 55, has had diabetes insipidus for at least twenty years. Probably he has liad the condition longer, for twenty-five years ago he noticed that he was passing an unusually large amount of urine and that he was more thirsty. There is nothing in his past history to indicate the cause of the disease. He has led a very regular life, and his only excess has been bicycling. From the age of 18 to 35 he was accustomed to ride very long distances, often doing one hundred miles in a day, and riding all the test hills.

During the last twenty-five years the amount of urine passed has varied between 9 and 15 pints, the average amount in the twenty-four hours being 11 to 12 pints. He has suffered no discomfort beyond the inconvenience of having to micturate frequently and the excessive thirst. At one time he used to drink beer and whisky, but he found he required such a large amount of fluid that he soon gave up alcohol, and for many years has taken only plain water. In cold weather he drinks it warm, as he finds that this quenches his thirst more readily.

His general health is good, and he leads an energetic life. His weight has not varied for many years. He usually has a furred tongue, and is inclined to constipation. His blood pressure is normal (130 $\mathrm{mm}$. Hg), but his pulse. is always rapid (90 to 100). He has had various spells of treatmcnt, but no drug has had any effect in reducing the amount of urine. After a course of ergot he developed boils. Restriction of fluid mercly increases the thirst, so for many years he has taken a glass of water, day and night, whenever he felt the desire; and, as his worls is in his own shop, he has been able to carry on in spite of the frequent calls to pass water. He drinlss over two gallons a day. The urine has for many years been pale and watery, acid in reaction, and with a specific gravity of 1002 to 1005 . Occasionally there has bcen a faint trace of albumin, but never any sugar.

During the winter 1920-2l he first noticed pain in the suprapubic region, and at the end of the penis, on passing water, with increasing frequency and some hesitation. As the weather got warmer this trouble diminished, but lie still had occasional pain in the penis, and felt that he was not emptying his bladder completely. 'Throughout the suramer he was practically free from pain, but in the late autumn of 1921 the difficulty of emptying the bladder ereturned, with resulting increased frcquency and pain. By the end of the winter the trouble had so much increased that he was not getting sufficient sleep, and was becoming quite worn out. The urine had for some time contained staphylococci and coliform bacilli, but as neither drugs nor vaccines improved the condition removal of the prostate was decided on.

\section{Surgical Report.}

Mr. Kidd's report is as follows :

"The patient was referred to me by Dr. Alexander on March 1st, 1922. He stated that for the last three months the had had great pain in the bladder region, a constant desire to pass water, which took a long time to come, and then only came in driblets. He was in pain all the time; he had to get up at least eight times during the night; in fact, his condition was becoming unbearable.

"Abdominal examination showed that he had a giant bladder well up to the umbilicus. Rectal examination revealed cons:derable enlargement of the prostate gland of an adenomatous type. The urethroscope showed no stricture present. The Wassermann reaction was negative. X-ray examination showed no stone present, but a picture taken of the skull revealed hollowing and excavation of the pituitary fossa, suggesting that there was a cystic enlargement of the pituitary gland. ... Ten to 12 pints of urine were passed in the twenty-four hours, which was very pale, speciflc gravity 1001 , and contained no pus, albumin, nor sugar.

"I looked upon the giant bladder as the result of the diabetes insipidus, and not as a sign of advanced vesical and renal failure, as there were no clinical signs whatever of renal failure. Abandoning my usual custom in the case of giant bladder, I therefore resolved to pass a catheter for the purpose of renal function tests. Indigo injected into a muscle of the leg came through the kidneys in eight minutes; and in less than half an hour it had stained the urine a deep blue colour. This shows the value of time tests of renal function. The dilute urine made no difference whatever to the indigo test. The blood urea was $10.7 \mathrm{mg}$. per $100 \mathrm{c.cm}$. of blood, a very low quantity (the normal being 15 to $40 \mathrm{mg}$. to 100 c.cm. of blood). The exact significance of this I do not know; but the observation appears to be of interest.

" Urea concentration test $=1$ st hour $-730 \mathrm{c.cm}$. of urine came through the catheter, specific gravity 1003 , urea 0.4 per cent., total urea 2.92 grams; 2nd hour -770 c.cm. urine, specific gravity 1003, urea 0.4 per cent., total urea 2.98 grams.

"Cystoscopy showed a very definite but quite small middle lobe and two small lateral lobes projecting upwards into the bladder, with marked trabeculation of the bladder.

"Operation was performed in one stage on March 10th, 1922. The prostate was enucleated. It consisted of two small lateral lobes and a small valvular middle lobe.

"After the operation the patient made 11 to 13 pints of urine a day, and it had to be collected in two large slop pails. He was passing all his urine naturally on the seventeenth day and went home soundly healed on the twenty-seventh day, passing 11 pints of urine freely with a good stream and without pain."

Five months after the operation the patient's condition is altogether satisfactory; his general health is very good, and he is free from all pain. He passes his urine with a good stream, though he states that towards the end of micturitign he feels as if he had to use his abdominal muscles to help. He has, for him, good nights, only having to get up two or three times. In the day he can hold his water two and a half to three hours: he still passes 10 to 12 pints of clear watery urine in the twenty-four hours, 